Hope College

Hope College Digital Commons

Faculty Publications

$3-2010$

\title{
An Electrochemical Cell for the Efficient Turn Around of Wafer Working Electrodes
}

Nicholas Wozniak

Hope College

Alyssa Frey

Hope College

Lucas Osterbur

Hope College

Timothy Boman

Hope College

Jennifer R. Hampton

Hope College, hampton@hope.edu

Follow this and additional works at: https://digitalcommons.hope.edu/faculty_publications

Part of the Analytical Chemistry Commons, and the Biological and Chemical Physics Commons

\section{Recommended Citation}

Wozniak, Nicholas, Alyssa Frey, Lucas Osterbur, Timothy Boman and Jennifer R. Hampton. "An Electrochemical Cell for the Efficient Turn around of Wafer Working Electrodes." Review of Scientific Instruments 81, no. 3 (2010). http://dx.doi.org/10.1063/1.3360849

This Article is brought to you for free and open access by Hope College Digital Commons. It has been accepted for inclusion in Faculty Publications by an authorized administrator of Hope College Digital Commons. For more information, please contact digitalcommons@hope.edu. 


\title{
An electrochemical cell for the efficient turn around of wafer working electrodes
}

\author{
Nicholas R. Wozniak, Alyssa A. Frey, ${ }^{a}{ }^{2}$ Lucas W. Osterbur, ${ }^{\text {b) }}$ \\ Timothy S. Boman, and Jennifer R. Hampton ${ }^{\text {c) }}$ \\ Department of Physics, Hope College, Holland, Michigan 49423, USA
}

(Received 16 October 2009; accepted 19 February 2010; published online 22 March 2010)

\begin{abstract}
We present a new design for an electrochemical cell for use with wafer working electrodes. The key feature of the design is the use of half turn thumb screws to form a liquid-tight seal between an o-ring and the sample surface. The assembly or disassembly of the cell requires a half turn of each thumb screw, which facilitates the quick turn around of wafer samples. The electrochemical performance of the cell is demonstrated by cyclic voltammetry and double step chronoamperometry measurements of the ferricyanide/ferrocyanide couple. () 2010 American Institute of Physics.
\end{abstract}

[doi:10.1063/1.3360849]

\section{INTRODUCTION}

Wafer shaped working electrodes, of either rectangular or circular cross section, are used in a wide range of electrochemistry experiments. An advantage of the wafer geometry is that after an electrochemical modification is performed, the sample can be examined ex situ with a variety of other surface analytical techniques, including scanning probe microscopy, optical spectroscopy or microscopy, and electron or ion beam characterization methods. If a wafer working electrode is desired, however, consideration must be given to the electrochemical cell used. An electrochemical cell will only function successfully with wafer working electrodes if the liquid electrolyte is in contact with the face of the wafer in a defined geometry without being allowed to touch the edges of the wafer. Although the use of wafer working electrodes is relatively common, there are only a handful of cell designs currently published.

One common design defines the working electrode area with the "inverted drop cell" method. In this method, a single drop of electrolyte is placed on the working electrode and the reference and counter electrodes are inserted into the drop. ${ }^{1}$ This works well for aqueous electrolytes and wafers that are relatively hydrophobic, but the volume of the electrolyte used is limited to the size of the drop that can be maintained. A related method is the use of a capillary to define a drop of electrolyte on the surface of the sample. ${ }^{2-5}$ In this case, the reference and counter electrodes are introduced through the top of the capillary. The working area of the electrode is defined either by surface tension between the capillary and the surface or by a rubber gasket at the capillary end. The design can be modified to allow electrolyte flow ${ }^{5}$ or to move the capillary with respect to the surface in order to interrogate different regions (the "scanning droplet cell").,

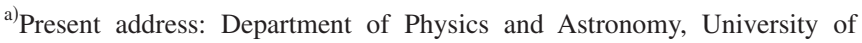
Wisconsin-Eau Claire, Eau Claire, Wisconsin, USA.

${ }^{b)}$ Present address: Department of Materials Science and Engineering, University of Illinois at Urbana-Champaign, Urbana, Illinois, USA.

c)Electronic mail: hampton@hope.edu.
}

An additional method involves defining the working electrode area with either an inert o-ring ${ }^{6-11}$ or with a Teflon piece that is machined and finely polished. ${ }^{12-14}$ In either case, the o-ring or Teflon piece must be firmly pressed to the sample in order to ensure a liquid-tight seal. This is often accomplished by screws that are either tightened with bolts or screwed directly into a tapped section of the cell. ${ }^{7,10,12,13}$ One specific cell, designed by Compton and co-workers, used a spring mechanism to press an o-ring to their HOPG sample, minimizing the damage to the soft graphite surface. ${ }^{11}$ For some other published cell designs, although the interface between the o-ring or Teflon and the sample is shown, the method used to maintain a liquid-tight seal is not indicated. ${ }^{6,8,9,14}$ Other groups mention custom-designed cells but do not describe them in detail. ${ }^{15-19}$

Here, we present a new design of an electrochemical cell for use with wafer working electrodes. The main feature of this design is the use of thumb screws to press two Teflon pieces together, making a liquid-tight seal between an o-ring and the sample. Because only a half turn of each thumb screw is needed to assemble or disassemble the cell, the design is particularly suited to the quick turn around of samples. We present data on the electrochemical performance of this cell design for both cyclic voltammetry and chronoamperometry of the $\mathrm{Fe}(\mathrm{CN})_{6}^{3-} / \mathrm{Fe}(\mathrm{CN})_{6}^{4-}$ couple. The reduction of ferricyanide to ferrocyanide, $\mathrm{Fe}(\mathrm{CN})_{6}^{3-}+e^{-}$ $\rightarrow \mathrm{Fe}(\mathrm{CN})_{6}^{4-}$, is a well-characterized reversible reaction. As a result, it is often used as a model system for demonstrating electrochemical principles. ${ }^{20}$

\section{CELL DESIGN}

Figure 1 shows a schematic cross section of the Teflon cell. Two rectangular pieces of Teflon, the base and the reservoir, form the main part of the cell. The base has a raised edge on all four sides so that when assembled, the reservoir sits on top without moving. In addition, the base has a square recessed area in the center for the working electrode, or sample, to sit. The dimensions of this recessed area were 


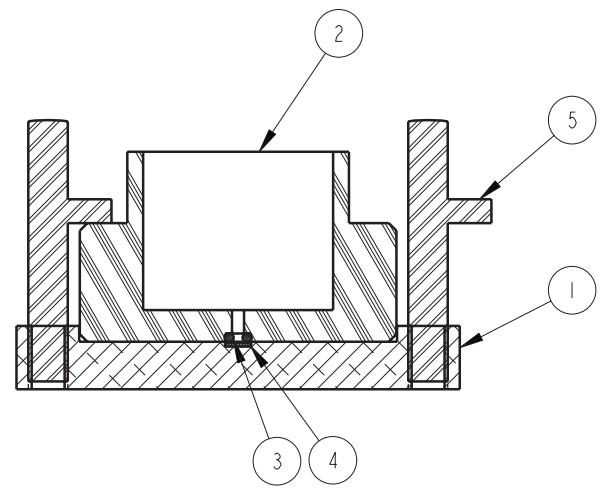

FIG. 1. A schematic cross section of the cell, showing (1) the Teflon base, (2) the Teflon reservoir, (3) the perfluoroelastomer o-ring, (4) the working electrode, and (5) the two half turn thumb screws. On the left, the thumb screw is shown turned into position holding the reservoir securely to the base. On the right, the thumb screw is shown turned out of position, allowing the reservoir to be lifted from the base. The reference and counter electrodes are placed in the cylindrical well of the reservoir to make contact with the electrolyte.

designed to fit $5 \times 5 \times 1 \mathrm{~mm}^{3}\left(0.197 \times 0.197 \times 0.0394\right.$ in. $\left.^{3}\right)$ wafer samples. Samples that are thinner than $1 \mathrm{~mm}$ can be accommodated with the same design by placing mylar shims of the appropriate thickness under the sample to raise it so that it is flush with the Teflon.

The reservoir has a cylindrical well to hold the electrolyte. At the bottom of the well there is a $2.38 \mathrm{~mm}(3 / 32 \mathrm{in}$.) diameter through hole where the electrolyte makes contact with the working electrode. To ensure a liquid-tight seal, a Kalrez $^{\circledR}$ perfluoroelastomer o-ring (McMaster-Carr, Chicago, IL) with an outer diameter of $5.16 \mathrm{~mm}$ (13/64 in.) and an inner diameter of $1.98 \mathrm{~mm}(5 / 64 \mathrm{in}$.) is used to define the area of the working electrode available for electrochemical reactions. The o-ring is placed in a recessed area on the underside of the reservoir so that when assembled, it is flush with the Teflon.

To make electrical connection to the top of the working electrode, a piece of $50.8 \mu \mathrm{m}(2 / 1000 \mathrm{in}$.) thick copper foil (McMaster-Carr, Chicago, IL) with a $5.16 \mathrm{~mm}$ (13/64 in) hole in it is placed on top of the base and taped into position so that the hole is centered on the working electrode. When the reservoir is placed on the base, the foil is sandwiched between the two Teflon pieces with a tab of the foil protruding from the edge of the cell. A standard alligator clip is used to connect to the copper tab and therefore to the corners of the working electrode. This completes the circuit from the working electrode, through the alligator clip, the copper foil, the top of the sample surface, and the electrolyte, to the counter electrode.

The choice of the size of the hole in the foil is a balance between maximizing the area of overlap between the copper and the sample surface and reducing the chances of contact between the copper and the electrolyte, which would allow electrochemical reactions to occur there. The size used in this design, the same as the outer diameter of the o-ring, typically resulted in a few hundred $\Omega$ of measured resistance between the working and counter electrodes, mainly due to the contact resistance between the copper and the sample surface. With this design, no unwanted reactions due to the copper were seen in electrochemical measurements. The copper foil can be reused for a number of trials; however, eventually the sides of the hole become distorted so that the copper does not make a good electrical connection to the sample. When this occurs, the copper foil can be discarded, and a new foil used in its place.

When assembled, the base and the reservoir are held together with two steel half turn thumb screws (Reid Supply Co., Muskegon, MI). These screw into the sides of the base, and when turned into position, press down on sides of the top of the reservoir, securing it in place and ensuring a liquidtight seal. The cell can be assembled and disassembled with a half turn of each of the thumb screws, without unscrewing them from the base, so swapping out working electrode samples can be done quickly and easily.

When assembled and filled with electrolyte, an air bubble can become trapped in the through hole that connects the reservoir to the sample face, causing the cell to not function properly. In order to remove air bubbles at the liquidsample interface, a pipette is used to extract the liquid and air in that region of the cell. This causes additional liquid from the reservoir to backfill the space. This procedure must be done each time the cell is assembled, and particularly after each time the electrolyte is purged with inert gas.

\section{CELL PERFORMANCE}

\section{A. Experimental procedures}

To investigate the performance of the cell, cyclic voltammetry and chronoamperometry measurements were used. The wafer working electrodes were approximately 5 $\times 5 \mathrm{~mm}^{2}$ samples diced from a $525 \mu \mathrm{m}$ thick silicon wafer plated with $1000 \AA$ of gold over $50 \AA$ of titanium (for adhesion) (Platypus Technologies, LLC, Madison, WI). The wafers were cleaned by sonicating them for $5 \mathrm{~min}$ in a $70 \%$ ethanol solution and dried using nitrogen gas. Solutions of 5 $\mathrm{mM} \mathrm{K}{ }_{3} \mathrm{Fe}(\mathrm{CN})_{6}$ and $1 \mathrm{M} \mathrm{KCl}$ were prepared with medical grade water and chemicals purchased from Sigma-Aldrich (St. Louis, MO). A BAS Epsilon Electrochemical Workstation (Bioanalytical Systems, Inc., West Lafayette, IN) was used with an $\mathrm{Ag} / \mathrm{AgCl}$ reference electrode (Bioanalytical Systems, Inc., West Lafayette, IN) and a platinum wire (Alfa Aesar, Ward Hill, MA) counter electrode. Nitrogen gas was bubbled through the electrolyte for five minutes before each experiment to purge it of dissolved electroactive gasses. After this initial purging, the nitrogen was used as a blanket in the air space above the electrolyte during each experiment to minimize the uptake of other electroactive gasses.

For cyclic voltammetry measurements, the potential was swept from 600 to $0 \mathrm{mV}$ and back again at a scan rate between 5 and $500 \mathrm{mV} / \mathrm{s}$ and the current was measured as a function of potential. For the chronoamperometry measurements, the potential was stepped from 600 to $0 \mathrm{mV}$ and back again with a step time of $5 \mathrm{~s}$ and the current was measured as a function of time. Potentials are reported with respect to the $\mathrm{Ag} / \mathrm{AgCl}(3 \mathrm{M} \mathrm{NaCl})$ reference, and currents are reported using the IUPAC convention, with anodic currents positive. 


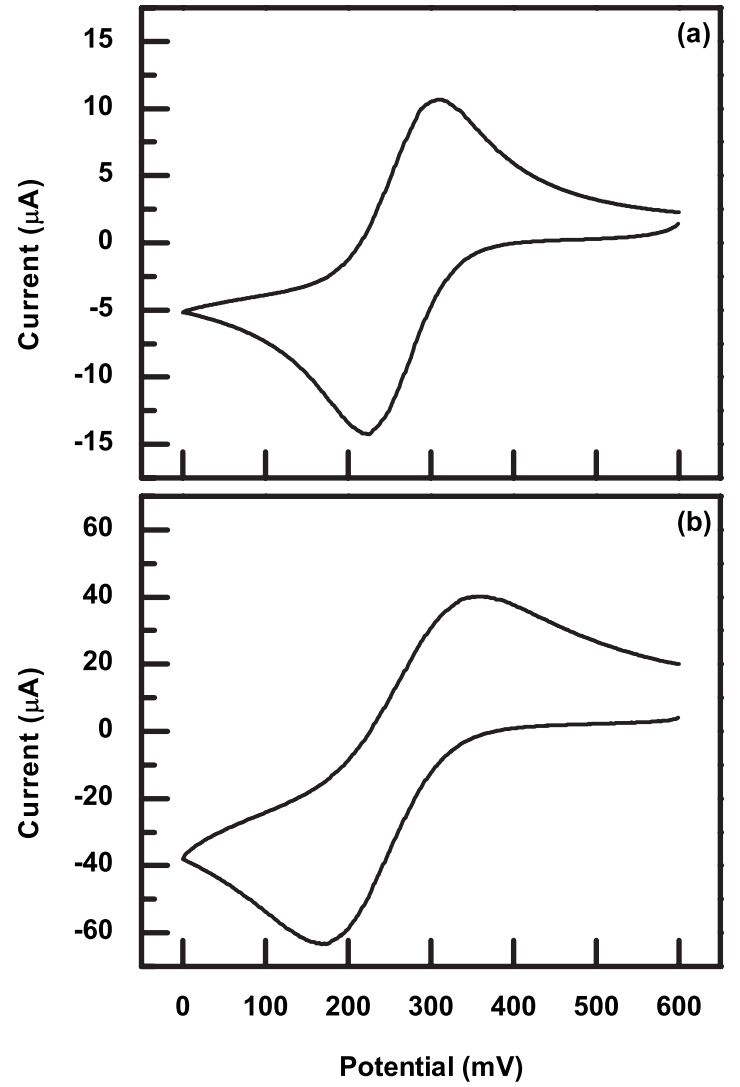

FIG. 2. Cyclic voltammograms of $5 \mathrm{mM} \mathrm{K}_{3} \mathrm{Fe}(\mathrm{CN})_{6}$ and $1 \mathrm{M} \mathrm{KCl}$ at a scan rate of (a) 10 and (b) $250 \mathrm{mV} / \mathrm{s}$.

\section{B. Cyclic voltammetry}

Figure 2 shows cyclic voltammograms of $5 \mathrm{mM}$ $\mathrm{K}_{3} \mathrm{Fe}(\mathrm{CN})_{6}$ and $1 \mathrm{M} \mathrm{KCl}$ at scan rates of 10 and $250 \mathrm{mV} / \mathrm{s}$. The voltammogram shape seen for the slower scan rate, Fig. 2(a), is similar to that predicted for a reversible one-electron electrochemical reaction, which has symmetric cathodic and anodic peaks separated by $\sim 59 \mathrm{mV} .^{21}$ However, for the faster scan rate, Fig. 2(b), the distortion in the voltammogram shape, in particular the less symmetric peaks and larger peak separation, is evidence of uncompensated resistance. For the largest scan rates of each trial, the cathodic peak currents were below $100 \mu \mathrm{A}$. Thus, for the largest measured currents and a contact resistance of a few hundred $\Omega$, the uncompensated potential drop at the copper foil-sample interface was as high as a few tens of millivolt.

The magnitude of the cathodic peak current, $i_{p}$, is graphed as a function of the square root of the scan rate, $v^{1 / 2}$, in Fig. 3 for one trial using a single working electrode sample. The error bars are the standard deviation of the residuals from the linear fit to the data, which is shown with the dashed line. The quality of the linear fit over this range of scan rates and currents is evidence that the cell performs effectively in this regime and uncompensated resistance does not significantly affect the peak size.

From the linear fit, the electrochemical area of the working electrode, $A$, was calculated using the Randles-Sevcik equation, ${ }^{21}$

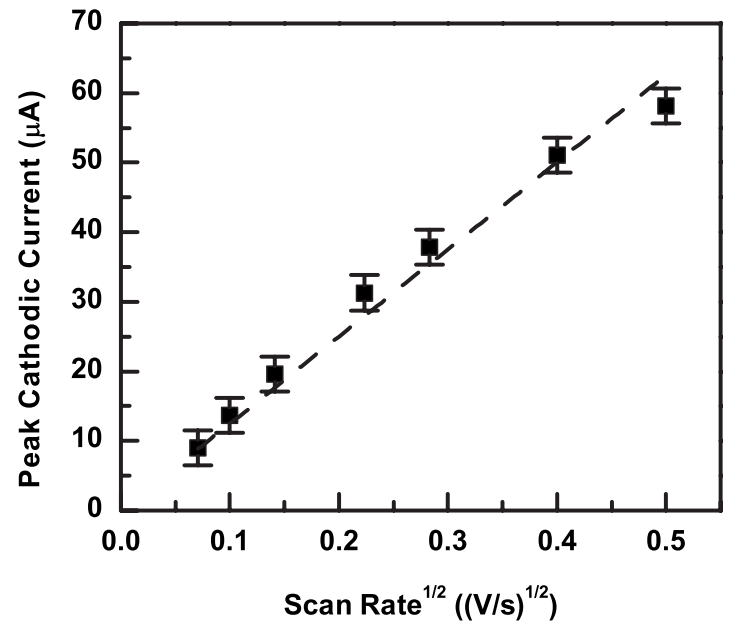

FIG. 3. The magnitude of the peak cathodic current, $i_{p}$, as a function of the square root of the scan rate, $v^{1 / 2}$, for one working electrode trial. The dashed line is a linear fit to the $i_{p}$ vs $v^{1 / 2}$ data for the trial. The electrochemical area of this electrode was found to be $0.0341 \pm 0.0010 \mathrm{~cm}^{2}$.

$$
i_{p}=0.4463 n F A C\left(\frac{n F}{R T}\right)^{1 / 2} v^{1 / 2} D^{1 / 2},
$$

where $n=1$ is the number of electrons involved in the electrochemical reaction, $F$ is Faraday's constant, $C=5$ $\times 10^{-3} \mathrm{~mol} / \mathrm{cm}^{3}$ is the bulk concentration of the $\mathrm{Fe}(\mathrm{CN})_{6}^{3-}$ analyte, $R$ is the molar gas constant, $T=298 \mathrm{~K}$ is the temperature, and $D=7.6 \times 10^{-6} \mathrm{~cm}^{2} / \mathrm{s}$ is the diffusion constant of the analyte. Figure 4 shows the electrochemical area of the working electrodes for ten trials as determined from cyclic voltammetry. Each trial used a new $\mathrm{Au} / \mathrm{Si}$ wafer sample. The unweighted average area for all the trials $\left(0.032 \mathrm{~cm}^{2}\right)$ is indicated by the solid line, while the dashed lines represent the average plus and minus the standard deviation of the trials $\left(0.005 \mathrm{~cm}^{2}\right)$.

For these electrodes, the variation in the area between trials is larger than the typical uncertainty in the determination of a single area, as indicated by the error bars on the data points. The performance of the cell was sufficient to reveal

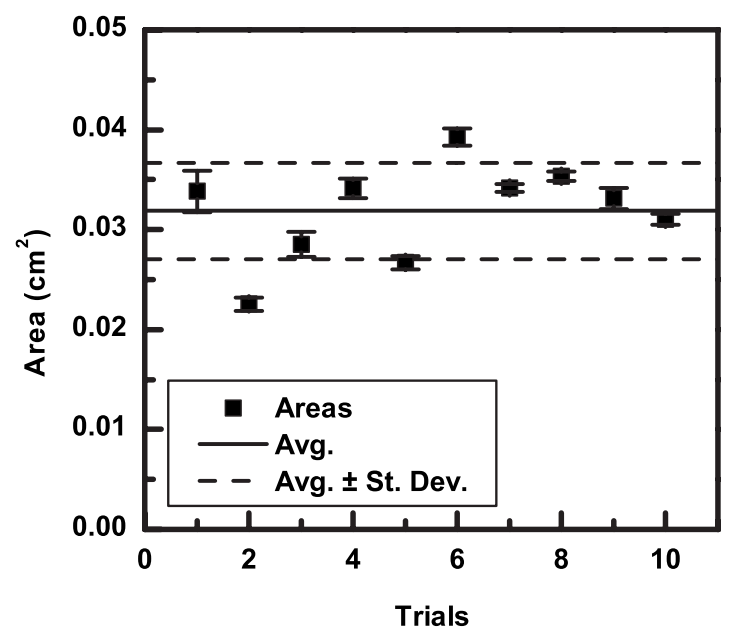

FIG. 4. The electrochemical area of the Au/Si working electrodes for ten trials. The unweighted average area for all the trials is indicated by the solid line, while the dashed lines represent the average plus and minus the standard deviation of the trials. 


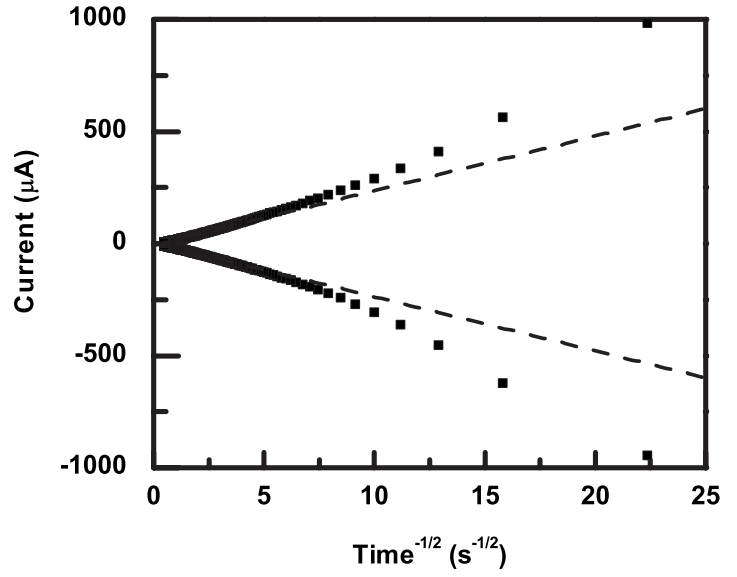

FIG. 5. Double step chronoamperometry of $5 \mathrm{mM} \mathrm{K}_{3} \mathrm{Fe}(\mathrm{CN})_{6}$ and $1 \mathrm{M} \mathrm{KCl}$ from $600 \mathrm{mV}$ to $0 \mathrm{mV}$ and back to $600 \mathrm{mV}$ with a step time of $5 \mathrm{~s}$. The dashed lines are linear fits to the $i$ vs $t^{-1 / 2}$ data for all the currents below $100 \mu \mathrm{A}$.

these differences in effective area using cyclic voltammetry. The observed variation in effective areas is likely due to differences in the morphology of the polycrystalline gold layer between different $\mathrm{Au} / \mathrm{Si}$ samples.

\section{Chronoamperometry}

Figure 5 shows the results of double step chronoamperometry with $5 \mathrm{mM} \mathrm{K}_{3} \mathrm{Fe}(\mathrm{CN})_{6}$ and $1 \mathrm{M} \mathrm{KCl}$. The current, $i$, is graphed as a function of the inverse square root of the time after the step, $t^{-1 / 2}$. The dashed lines are linear fits to $i$ versus $t^{-1 / 2}$ for all the currents below $100 \mu \mathrm{A}$. The deviations from linearity at high currents (short times) are due to the uncompensated resistance at the copper-sample interface and the capacitance at the sample-electrolyte interface. ${ }^{21}$ From the slopes of the linear fits, the electrochemical area of the working electrode was calculated using the Cottrell equation, ${ }^{21}$

$$
i(t)=\frac{n F A D^{1 / 2} C}{\pi^{1 / 2} t^{1 / 2}} .
$$

The results for the cathodic and anodic steps, $0.0319 \pm 0.0004$ and $0.0323 \pm 0.0004 \mathrm{~cm}^{2}$, respectively, compare favorably to the average area of the gold electrodes found with cyclic voltammetry.

\section{CONCLUSION}

We have designed a new Teflon electrochemical cell for use with wafer working electrodes. A key feature of the design is the use of half turn thumb screws, which allow samples to be exchanged quickly and simply. The design was implemented for $5 \times 5 \times 1 \mathrm{~mm}^{3}$ wafer samples; however, the dimensions of the design are flexible, and could be adapted to other sizes of wafer. For this design, the effective electrode area $\left(3 \times 10^{-2} \mathrm{~cm}^{2}\right)$ is at the upper end of the range of areas obtainable by capillary-based droplet cells. ${ }^{4}$ Smaller effective areas can be obtained by using a smaller o-ring, but for extremely small sizes, the ability to obtain and maintain good electrical connection between the electrolyte and the sample face may become problematic. For the design as implemented, robust cell performance was demonstrated with cyclic voltammetry and chronoamperometry measurements using the ferricyanide/ferrocyanide couple.

\section{ACKNOWLEDGMENTS}

The authors thank Dr. T. J. Mullen for helpful discussions and Dave Daugherty for discussions about the cell design and for machining the cell. This material is based on work supported by the National Science Foundation under NSF-REU Grant No. 0452206, the Hope College Dean for the Natural and Applied Sciences Office, and the Hope College Department of Physics.

${ }^{1}$ M. T. McDermott, K. Kneten, and R. L. McCreery, J. Phys. Chem. 96, 3124 (1992).

${ }^{2}$ T. Suter and H. Böhni, Electrochim. Acta 42, 3275 (1997).

${ }^{3}$ A. W. Hassel and M. M. Lohrengel, Electrochim. Acta 42, 3327 (1997).

${ }^{4}$ M. M. Lohrengel, A. Moehring, and M. Pilaski, Electrochim. Acta 47, 137 (2001).

${ }^{5}$ M. M. Lohrengel, C. Rosenkranz, I. Klüppel, A. Moehring, H. Bettermann, B. V. Bossche, and J. Deconinck, Electrochim. Acta 49, 2863 (2004).

${ }^{6}$ E. Peiner and A. Schlachetzki, J. Electrochem. Soc. 139, 552 (1992).

${ }^{7}$ S. A. Hendricks, Y.-T. Kim, and A. J. Bard, J. Electrochem. Soc. 139, 2818 (1992)

${ }^{8}$ L. Torcheux, A. Mayeux, and M. Chemla, J. Electrochem. Soc. 142, 2037 (1995).

${ }^{9}$ H.-D. Lee, H.-J. Lee, C.-K. Kim, and C.-H. Han, Appl. Phys. Lett. 66, 3272 (1995)

${ }^{10}$ J. D. Noll, M. A. Nicholson, P. G. V. Patten, C. W. Chung, and M. L. Myrick, J. Electrochem. Soc. 145, 3320 (1998).

${ }^{11}$ R. Bowler, T. J. Davies, M. E. Hyde, and R. G. Compton, Anal. Chem. 77, 1916 (2005).

${ }^{12}$ D. R. Yaniv and P. S. Jung, Electroanalysis 7, 260 (1995).

${ }^{13}$ V. Bertagna, F. Rouelle, and M. Chemla, J. Appl. Electrochem. 27, 1179 (1997).

${ }^{14}$ N. Mitsugi and K. Nagai, J. Electrochem. Soc. 151, G302 (2004).

${ }^{15}$ R. J. Bowling, R. T. Packard, and R. L. McCreery, J. Am. Chem. Soc. 111, 1217 (1989).

${ }^{16}$ J. V. Zoval, R. M. Stiger, P. R. Biernacki, and R. M. Penner, J. Phys. Chem. 100, 837 (1996).

${ }^{17}$ N. S. Pesika, A. Radisic, K. J. Stebe, and P. C. Searson, Nano Lett. 6, 1023 (2006).

${ }^{18}$ T. J. Mullen, A. A. Dameron, and P. S. Weiss, J. Phys. Chem. B 110, 14410 (2006).

${ }^{19}$ X. Bin, T. K. Mischki, C. Fan, G. P. Lopinski, and D. D. M. Wayner, J. Phys. Chem. C 111, 13547 (2007).

${ }^{20}$ J. J. Van Benschoten, J. Y. Lewis, W. R. Heineman, D. A. Roston, and P. T. Kissinger, J. Chem. Educ. 60, 772 (1983).

${ }^{21}$ A. J. Bard and L. R. Faulkner, Electrochemical Methods: Fundamentals and Applications, 2nd ed. (Wiley, New York, 2001). 